\title{
ABNORMAL ARRANGEMENT OF THE LOWER LUMBAR AND FIRST SACRAL NERVES WITHIN THE SPINAL CANAL
}

\author{
Bryan Keon-Cohen, Melbourne, Australia
}

In 1952 Ethelberg and Riishede reported four cases in which the patients were subjected to operation because they presented with clinical manifestations strongly suggesting disc hernia. In each instance they found malformations of the lumbo-sacral plexus, disc hernia being also present in only two cases. Four more similar cases are reported in which five operations were performed. The findings at the fifth operation were perhaps the most significant.

\section{CASE REPORTS}

Case 1-A man aged 46 stated that five months ago he had strained his back at work lifting bags of cement. The pain was felt low on the left side, and later radiated down the left leg. He was unable to work for six weeks. The pain did not resolve completely and had recently become worse again, extending to the left foot. He walked with a forward stoop, favouring the left leg. All back movements, particularly flexion, were limited. Local tenderness was not marked but straight leg raising was markedly restricted. The left knee jerk was slightly diminished and the left ankle jerk was absent. There were sensory changes, mainly hyperaesthesia, over the lower part of the leg. Disc hernia probably affecting the fifth lumbar nerve root was suspected.

At operation a disc hernia was found and removed, but it was noted that the fifth lumbar and first sacral nerves appeared to arise from the same nerve root and to separate extrathecally. The disc hernia bulged posteriorly beneath both nerves at their conjoined point of emergence from the theca (Fig. 1).

Progress was slow but nine months after the operation the patient was passed fit for restricted employment. In reply to a recent follow-up enquiry he wrote that he was " fighting fit" at 60 and doing a full day's work, fourteen years after operation.

Case 2-A woman aged 32 felt sudden pain in the lower back while lifting a bundle of blankets. The pain was low down on the right side, and soon radiated down the right leg to the knee. It was severe and was aggravated by movement. She thought that the right leg felt weaker than the left. She moved with great caution, appeared to be in considerable pain, and favoured her right leg. Back

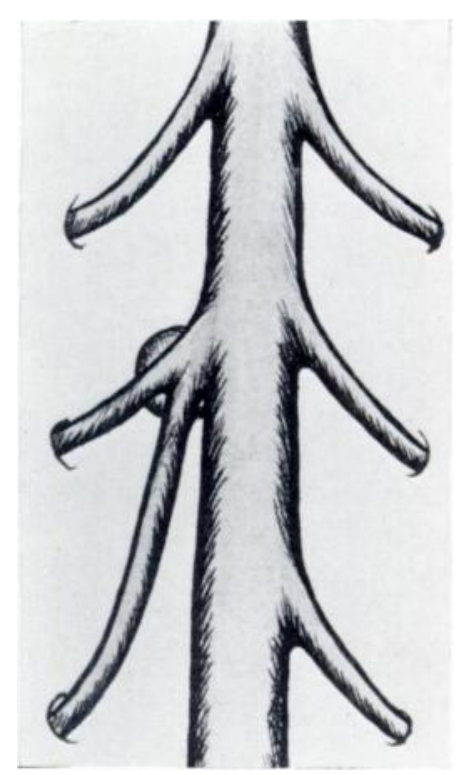

FIG. 1

Case 1-Findings at operation. The left fifth lumbar and first sacral nerves leave the theca by what appears to be a common root that divides extrathecally. A herniation from the disc between the fourth and fifth lumbar vertebrae projects beneath the common roots. movements were greatly limited. A " trigger point" was present low down on the right side and the Lasègue test was strongly positive on the right side. The right ankle jerk was absent. Disc hernia affecting the first sacral nerve root was diagnosed.

Operation-At operation no disc hernia was found but there was an abnormal arrangement of the fifth lumbar and first sacral nerve roots which were joined into a plexiform arrangement by a stout branch from the fifth lumbar about a centimetre lateral to the theca and running 
parallel to it to join the first sacral nerve. The anomaly was exactly similar to that reported by Ethelberg and Riishede in their second case (Fig. 2).

Progress-Progress was far from satisfactory. There was foot-drop, ascribed to operative trauma, and bizarre sensory changes that were thought to be functional. She was passed fit for suitable work a year after the operation. She failed to answer a recent follow-up enquiry.

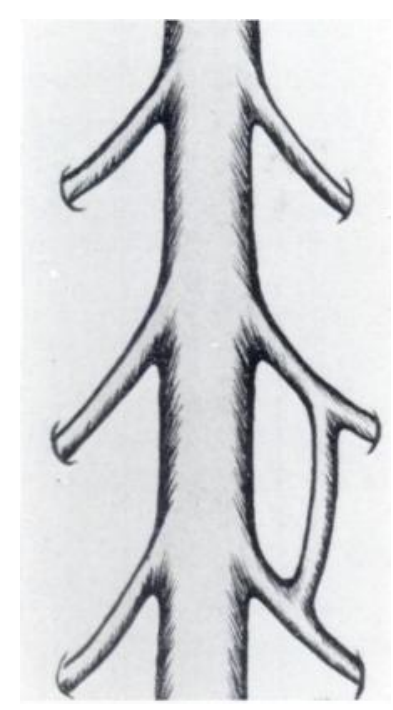

FiG. 2

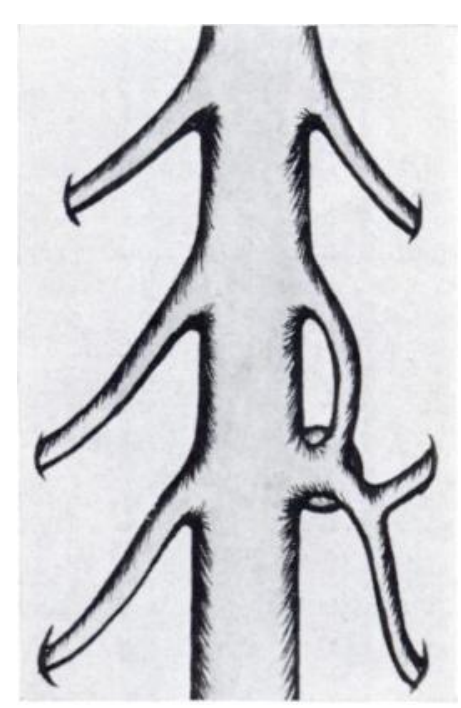

FiG. 3

Figure 2. Case 2--Findings at operation. Note the plexiform arrangement formed by a communication between the right fifth lumbar and first sacral nerves. Figure 3. Case 3-Findings at operation. Note the plexiform arrangement. The right fifth lumbar nerve appears to join the first sacral nerve; the nerves run together in a short segment and then separate. A herniation from the lumbo-sacral disc projects beneath the confluent portion of the nerves.

Case 3-A man aged 42, a master butcher, had strained his back while lifting a drum of tallow two years previously. Partial recovery followed rest, heat and analgesics. He favoured his right leg on bending forwards and the Lasègue test was positive. Although there were no other objective signs it was considered that there was probably a small disc hernia and a brace was accordingly fitted. A month later the patient was in severe pain. The ankle jerk was now absent and there were sensory changes in the lower leg.

Operation-At operation a large disc hernia affecting the first sacral nerve was found and removed. There was, however, an extra-thecal plexus inasmuch as the fifth lumbar nerve appeared to join the first sacral shortly after the latter emerged from the theca. They ran a common course for about a centimetre and then separated again. The disc hernia protruded immediately under the confluent course of the two nerve roots (Fig. 3).

Progress was uneventful and after six weeks he was back at his normal duties. He wrote in reply to a recent enquiry stating that he was still fit and well.

Case 4-A man aged 31, a machine operator, felt sudden pain low down in the left lumbar region while operating a fly-press. There was radiation down the back of the left thigh as far as the knee and also into the left groin. He had spent three weeks in hospital under treatment by his own doctor but was still unable to work. He had been wearing a brace without relief. All back movements were restricted, and on forward flexion he favoured his left leg. There was local tenderness to the left of the lumbar spine but no " trigger effect " on percussion. Both Lasègue tests were just positive. Reflexes were normal but there were vague, somewhat bizarre, sensory changes in the left lower leg. Plain radiographs were 
normal and myelography was uninformative. No improvement took place in the next two months, by which time he had been out of work for over three months. It was therefore decided to explore the lumbar spine on the tentative diagnosis of disc hernia.

Operation and progress - No disc hernia was found but the fifth lumbar and the first sacral nerves were conjoined as in Case 1. The fifth lumbar nerve passed directly transversely

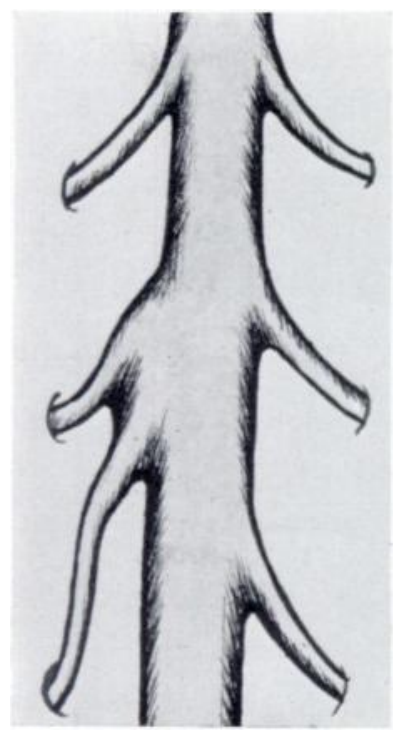

Fig. 4

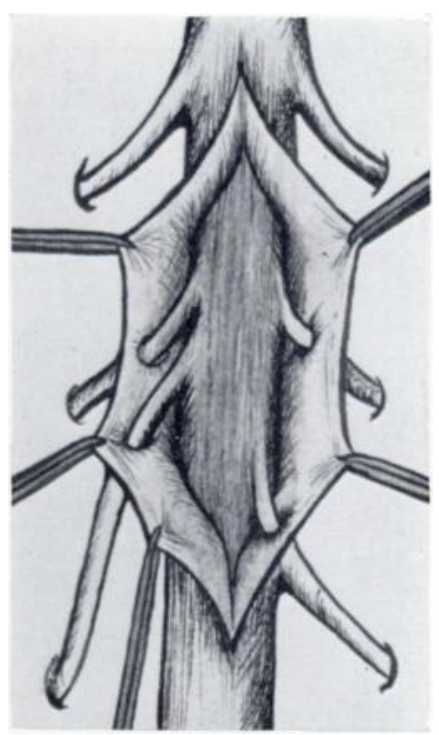

Fig. 5

Case 4-Findings at operations. Figure 4-First operation. The left fifth lumbar and first sacral nerves emerge by an apparently conjoined nerve root. Figure 5-Second operation. The theca has been opened. The fifth lumbar and first sacral nerves leave the theca by separate roots. They could be separated extradurally by careful dissection. No disc hernia was found.

from the common origin to its foramen, while the first sacral nerve ran a long extra-thecal, almost vertical, course to its exit (Fig. 4). Immediately after operation the pain was completely relieved, but within a few weeks of the patient's discharge from hospital it recurred. The physical signs were exactly as before except that now there was some diminution of the left ankle jerk. After six months he returned to restricted light work, still wearing a brace, but there was no real change in his condition. Because no real progress had been made after a further six months it was decided to re-explore the spine and this time to open the theca.

Operation-When the theca was opened it was found that there were, in fact, two nerve roots leaving the dura through separate exits, separated from one another by two or three millimetres. It was then realised that they might well be separate entities outside as well as inside and that it might be possible to establish this by careful dissection. This was in fact achieved, and the bulbous " root" which was at first thought to be one large conjoined nerve was shown to be two separate and distinct nerves, emerging from the theca through a communal sleeve and bound together extra-thecally by fibrous adhesions (Fig. 5).

Further progress-The patient was last seen ten months after the second operation, still wearing a brace. He had developed a "stocking type" anaesthesia which was certainly functional and he was still drawing compensation pay for being unfit for work. He answered a recent enquiry and stated that, nineteen months after operation, he was working again as a maintenance welder and fitter, not doing heavy work. He thought he was still making steady progress.

VOL. 50 B, NO. 2, MAY 1968 


\section{DISCUSSION}

The lumbar nerve roots were seen on one side only at operation in these cases. The arrangement on the other side is not known except in Case 4, in which the exits of the opposite nerves seemed to be normally spaced. In only three of the subsequent cases to be mentioned were the nerves on the opposite side seen. They too were apparently normal.

In 1954 Reynolds reported four cases of malformation of the lumbo-sacral plexus, namely three cases of conjoined nerve roots and one of extra-dural anastomosis. A disc hernia was found in each instance. He encountered great difficulty in mobilising the overlying nerve roots sufficiently to excise the protruding discs. Stimulated by the bad result after simple disc excision in his first case, and in an attempt to overcome the unusual fixation of the nerve roots, he divided the fifth lumbar component in two cases, and the anastomotic branch in another. In the latter instance only was the end result satisfactory, root section apparently making no difference in the other two. It is just possible therefore that this manoeuvre did on one occasion contribute towards a happy ending. It is worth noting that in only one instance, in which a very minor degree of foot-drop persisted, was there any significant consequence of nerve root section.

In 1962 Cannon, Hunter and Picaza reported five personal cases together with four others about which they had had communications from colleagues. Including those of Ethelberg and Riishede they classified these thirteen cases into three groups: 1) transverse nerve root; 2) conjoined nerve roots; 3 ) anastomosis between roots. In my view the transverse nerve root does not qualify for inclusion in a series of plexus abnormalities, because the degree of " transverseness" is a matter for personal judgment and is, in consequence, subject to a certain looseness in interpretation. It has been encountered on several occasions and has not even merited a mention in the operation notes. In fact, in the absence of disc hernia the notes merely record a " nil return" and in all probability an ill-advised operation. This rather harsh judgment may in the light of further knowledge prove to be not altogether justified.

TABLE I

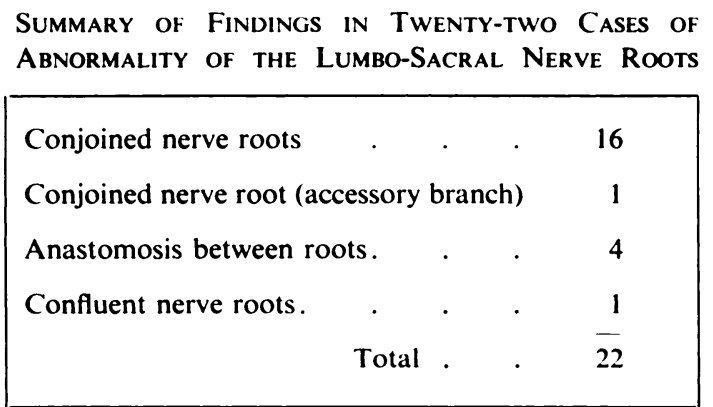

In twelve cases disc hernia was also present.

Two other cases are noted in the literature. In 1954, Deyerle and May reported a case of disc protrusion associated with a conjoined nerve root-in this instance with an accessory root arising in conjunction with the fifth lumbar nerve. McElvenny (1956) reported a true conjunction of the fifth lumbar and first sacral nerves, also associated with a disc hernia.

Including the four cases reviewed in this paper there are now documented records of twenty-two proved cases of malformations of the lumbo-sacral plexus (Table I). All the patients showed symptoms and signs strongly suggesting disc hernia, and were accordingly subjected to operation.

No doubt many other surgeons have encountered similar cases but, as Cannon et al. pointed out, the limited exposure favoured by neuro-surgeons could mean that others may have 
been overlooked. They even suggested that the large oedematous nerve root so often observed may on wider inspection prove to be, in fact, a conjoined nerve root. This is definitely not so in my experience, because I have never used the limited exposure.

Apart from the actual plexus abnormalities, the only really significant finding at operation was the relative fixation of the involved nerve roots. In my two cases in which a disc hernia was found in association with the malformation (Cases 1 and 3) great difficulty was encountered in mobilising the nerve roots in order to obtain sufficient exposure of the disc hernia so that it could be removed. Reynolds also noted this fixation and divided the offending components in an attempt to overcome it. Cannon et al. noted the same abnormal fixation, and in particular, the difficulty in exposing the disc hernia. They also regarded an abnormally transverse direction of a nerve as an abnormality causing increased fixation of the particular root as it passed directly to the foramen.

In most of the recorded cases the result could not be classed as satisfactory. It may well be that loss of normal mobility of nerve roots can be a cause of root pain. Certainly, root pain for which no adequate cause can be found even at operation is common enough.

Further study of more cases is required before a diagnosis of abnormality of the lumbosacral plexus can be established before operation. Myelography has so far proved singularly unhelpful. In twelve of the twenty-two reported cases protrusion of a disc was found at operation in addition to the anatomical abnormality: in these, the patient would probably have remained symptomless had there been no disc protrusion. Cannon et al. suggested that the absence of Lasègue's sign in association with features suggestive of disc protrusion might be significant. However, Lasègue's sign was present in all four cases recorded here. The fact that in Case 4 the roots which were separate entities intra-thecally could also be separated extra-thecally, may be important. It is possible that in other cases adhesion may have been mistaken for actual confluence or for an anastomotic loop.

\section{SUMMARY}

1. Four cases of abnormal arrangement of the lower lumbar and sacral nerves within the spinal canal are reported.

2. In all four cases the presentation was like that associated with acute lumbar disc protrusion, though in only two cases was a protrusion found at operation.

3. The significance of the findings is discussed and the findings are compared with those in the eighteen other recorded cases.

I am grateful to Mrs Ann Tolley for the diagrams.

\section{REFERENCES}

Cannon, B. W., Hunter, S. E., and Picaza, J. A. (1962): Nerve-root Anomalies in Lumbar-disc Surgery. Journal of Neurosurgery, 19, 208.

Deyerle, W. M., and May, V. R. (1954): Sciatica-Etiology and Treatment. Clinical Orthopaedics, 4, 166.

Ethelberg, S., and Rishede, J. (1952): Malformation of Lumbar Spinal Roots and Sheaths in the Causation of Low Backache and Sciatica. Journal of Bone and Joint Surgery, 34-B, 442.

McElvenny, R. T. (1956): Anomalies of the Lumbar Spinal Cord and Nerve Roots. Clinical Orthopaedics, $8,61$.

ReYNolds, F. C. (1954): The Intervertebral Disk: Surgical Technique. American Academy of Orthopaedic Surgeons, Instructional Course Lectures, 11, 121. 